\title{
Awake Intubation for a Case of Giant Parapharyngeal Space Tumor Using McGrath MAC $^{\circledR}$ Video Laryngoscope
}

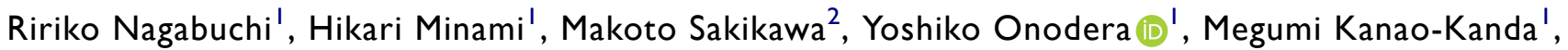 \\ Hirotsugu Kanda' \\ 'Department of Anesthesiology and Critical Care Medicine, Asahikawa Medical University, Asahikawa, Japan; ${ }^{2}$ Department of Dentistry and Oral \\ Surgery, Rinseikai Yoshida Hospital, Nayoro, Japan
}

Correspondence: Hirotsugu Kanda, Department of Anesthesiology and Critical Care Medicine, Asahikawa Medical University, Midorigaoka-higashi 2-I-I-I, Asahikawa, Hokkaido, 078-85I0, Japan, Tel +8I-166-68-2583, Fax +8I-I66-68-2589, Email h.kanda0629@nifty.com

Purpose: Intubation and ventilation cannot be performed in cases of parapharyngeal space tumors as the enlargement of the upper airway leads to the obstruction and hindrance of the intubation procedure. However, there is limited literature on anesthetic management, including the airway, in this disease. Herein, we report a successful case of awake intubation in a patient with parapharyngeal space tumor.

Case Presentation: A 64-year-old man with a history of giant parapharyngeal space tumor was scheduled for bilateral endoscopic sinus surgery and nasal septoplasty. We performed awake intubation using the McGrath ${ }^{\circledR}$ video laryngoscope, which resulted in excellent laryngeal deployment and a smooth procedure.

Conclusion: We report the anesthetic management of a giant parapharyngeal space tumor with the potential for difficult airway management to maintain spontaneous breathing. Awake intubation was useful in maintaining ventilation and intubation in this case. The preparation of a cricothyroid puncture is needed in cases of intubation failure.

Keywords: parapharyngeal space tumor, awake intubation, video laryngoscope

\section{Plain Language Summary}

We present the case of a 64-year-old man with a giant parapharyngeal space tumor scheduled for bilateral endoscopic sinus surgery and nasal septoplasty due to chronic nasal obstruction.

A difficult airway was anticipated; therefore, we decided to perform normal induction or awake intubation. Oral intubation was selected as the choice of airway as the scheduled surgery was a bilateral endoscopic sinus surgery rather than a surgery for the extirpation of the tumor. We selected the McGrath MAC video laryngoscope without a fiberscope as the intubation method. Midazolam and fentanyl were administered for mild sedation.

Tracheal intubation was performed using the McGrath MAC video laryngoscope, resulting in excellent laryngeal deployment, followed by successful endotracheal tube intubation without any specific event. The same methods of airway management, including the McGrath MAC video laryngoscope and the fiberscope were used during the preparation for re-intubation after extubation.

\section{Introduction}

Parapharyngeal space tumors are uncommon, accounting for approximately $0.5 \%$ of all head and neck tumors. These tumors are located in the suprahyoid neck, which resembles an inverted pyramid with its floor at the skull base and tip at the greater horn of the hyoid bone. 1,2 Parapharyngeal space tumors may lead to a "cannot intubate-cannot ventilate" situation as the tumor enlargement in the upper airway can cause obstruction and hindrance to the intubation procedure. Although there is literature on anesthesia management and awake intubation in cervical tumors, limited literature is available on anesthesia management, including airway management of parapharyngeal space tumors. Moreover, most of 
the available literature reported on the extraction or biopsy of the parapharyngeal space tumors instead of other types of surgery. ${ }^{3,4}$ Herein, we report a case of successful awake intubation in a patient with a parapharyngeal space tumor scheduled for a bilateral endoscopic sinus surgery.

\section{Case Presentation}

A 64-year-old man (height: $176 \mathrm{~cm}$; weight: $78.5 \mathrm{~kg}$ ) with a giant parapharyngeal space tumor was scheduled for bilateral endoscopic sinus surgery and nasal septoplasty due to chronic nasal obstruction. His medical history included sleep apnea, hypertension, hyperlipidemia, and hyperuricemia. Oral findings and computed tomography scan images showed that the parapharyngeal space tumor occupied the oropharynx, including the upper airway (Figure 1). In this case, a difficult airway was anticipated; thus, we decided to perform normal induction or awake intubation. Normal induction is less stressful for patients but may require invasive procedures, including cricothyroid puncture, in cases where airway management is impossible. Awake intubation is more stressful than normal intubation, but it is chosen in cases where airway management is difficult because spontaneous breathing can be maintained. After consultation with the involved otorhinolaryngologist, oral surgeon, and the patient, awake intubation was performed.

In the operating room, topical anesthesia was applied to the oropharyngeal mucosa using a $4 \%$ lidocaine spray. After waiting for a few minutes, the McGrath ${ }^{\circledR}$ MAC video laryngoscope was inserted, and lidocaine spray was applied again. A fiberscope was also inserted to visualize the glottis for intubation. Both the McGrath MAC video laryngoscope and the fiberscope provided an excellent viewing field for manipulation of intubation (Figure 2). Therefore, we selected the McGrath MAC video laryngoscope without a fiberscope as the intubation method. Midazolam $(2 \mathrm{mg})$ and fentanyl $(100 \mu \mathrm{g})$ were administered for mild sedation. Eventually, tracheal intubation was performed using the McGrath MAC video laryngoscope, resulting in excellent laryngeal deployment, followed by successful endotracheal tube intubation without any specific event. General anesthesia was quickly induced using propofol $(100 \mathrm{mg})$, fentanyl $(100 \mu \mathrm{g})$, and rocuronium $(60 \mathrm{mg})$ after confirmation of correct placement. Anesthesia was maintained with sevoflurane and continuous remifentanil infusion. The duration of surgery and anesthesia was 46 minutes and 74 minutes, respectively, and the patient recovered from general anesthesia and was extubated uneventfully. The same methods of airway management, including the McGrath MAC video laryngoscope and the fiberscope, were used during the preparation for re-intubation after extubation. All surgical procedures were performed successfully, and the patient was discharged 6 days postoperatively without complications. Written informed consent was obtained from the patient for the publication of this case.

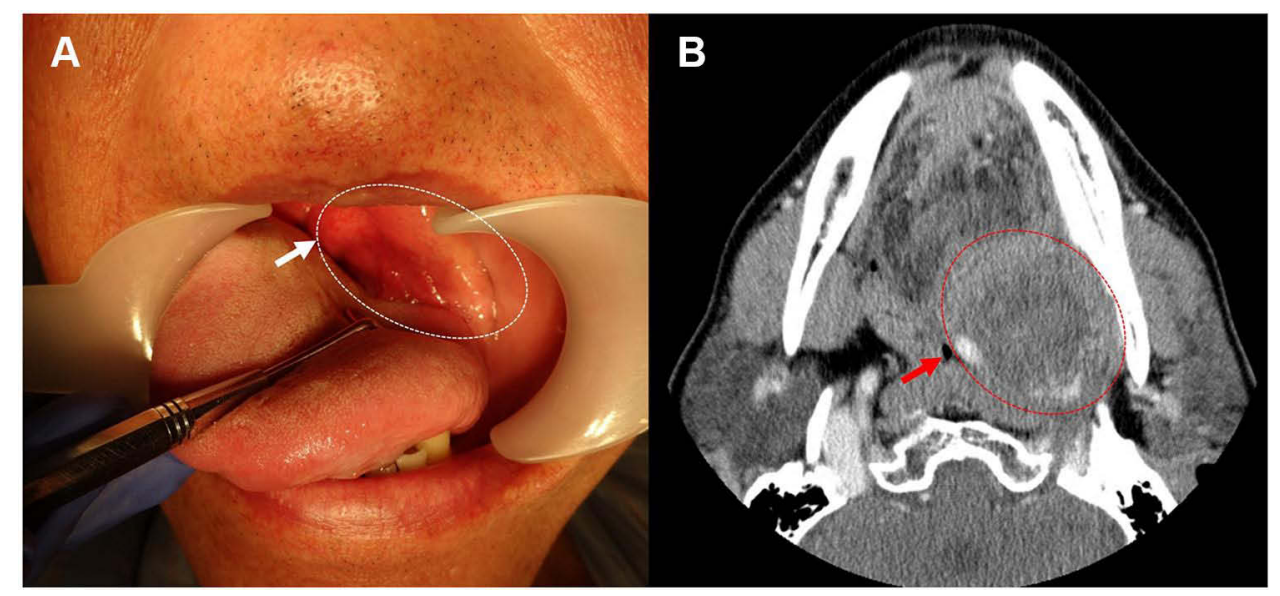

Figure I The oral finding (A) and computed tomography image of the tumor (B). The white dotted ellipse shows a giant parapharyngeal space tumor that occupying the oropharynx, including the upper airway. The white arrow indicates the deviation of the uvula to the right side. The red dotted line shows the giant parapharyngeal space tumor compressing the upper respiratory tract (red arrow). The size of the tumor is about $48.33 \times 37 \times 48 \mathrm{~mm}$. 


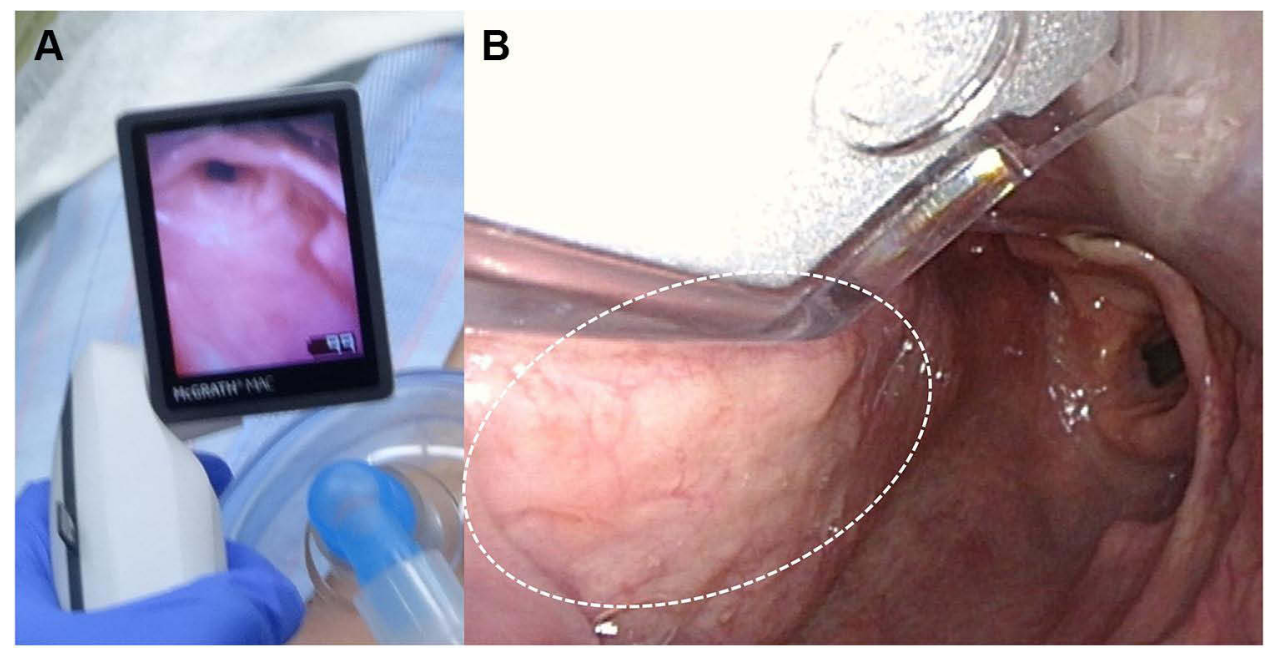

Figure 2 Laryngeal deployment with McGrath MAC video laryngoscope (A) and fiberoptic image (B). The vocal cords appear normal and were graded as Cormack I. Fiberoptic observation of the oral cavity reveals that the tumor has caused swelling of the left upper pharynx, with indistinct borders, and the oral cavity is slightly narrowed. The white dotted ellipse shows tumor compression by the McGrath blade.

\section{Discussion}

Awake intubation is indicated when a risk of "cannot intubate-cannot ventilate" is judged during the assessment of airway management. It is also an alternative for patients at high risk of aspiration, such as those with a full stomach. The American Society of Anesthesiologists' (ASA) difficult airway management (DAM) guidelines state that awake fiberoptic intubation is successful in $88 \%$ of cases of difficult airway management. ${ }^{5}$ In this case, anesthesia induction was performed according to the algorithm for awake intubation in the ASA's DAM guidelines. ${ }^{5}$ Both the JSA and ASA guidelines recommend invasive airway management, such as cricothyroid puncture, if the airway is difficult to secure. ${ }^{5,6}$ Finally, in this case, we could manage the airway without undertaking invasive measures, but it is necessary to be prepared in the event of a cricothyroid puncture.

We chose awake oral intubation for several reasons. In this case, the tumor was confined to the pharynx and was not in contact with the larynx. In addition, the tumor was not hemorrhagic, and the risk of bleeding from the laryngoscope blade was low. Moreover, the scheduled surgery was not the extirpation of the tumor but a bilateral endoscopic sinus surgery. Therefore, nasal intubation was not suitable in terms of impedance in the surgery course and chronic nasal obstruction. Nasal intubation might be considered a suitable airway choice in case of extirpation of the tumor. ${ }^{3}$ We used a McGrath video laryngoscope and the fiber because the video laryngoscope has a better field of view than the classic laryngoscope, and the fiber was prepared as an alternative method in cases where it was difficult to expand the laryngeal deployment with the McGrath. According to a survey conducted on Canadian anesthesiologists, a video laryngoscope, such as the McGrath video laryngoscope, was selected as the first-choice in cases of difficult intubation. ${ }^{7}$ Moreover, a wire-guided cricothyroidotomy was selected as the first-choice in cases of cannot intubate-cannot ventilation. ${ }^{7}$

Sung-Mi reported a case of a parapharyngeal space tumor. ${ }^{8}$ In a previous case, intubation could not be performed after anesthesia induction due to severe distortion of the glottis. Fiberoptic bronchoscopy and video laryngoscopy were ineffective, whereas retrograde wire intubation proved successful. The patient had a tumor detected postoperatively on magnetic resonance imaging. We could perform airway management in this patient without such invasive procedures. To the best of our knowledge, no previous report has described a case of noninvasive intubation in patients with parapharyngeal space tumors, and the present report is of great clinical value. Proper assessment during airway management can prevent invasive airway access and unexpected failure.

In conclusion, we report a case of anesthesia management of a patient with a giant parapharyngeal space tumor, which might have led to a difficult airway. Oral intubation was selected as the choice of airway as the scheduled surgery was a bilateral endoscopic sinus surgery rather than a surgery for the extirpation of the tumor. Awake oral intubation was useful in maintaining ventilation and intubation in this case. Cricothyroid puncture is required in cases of intubation failure. 


\section{Abbreviations}

ASA, American Society of Anesthesiologists; DAM, difficult airway management; JSA, Japanese Society of Anesthesiologists.

\section{Ethics Approval and Informed Consent}

The patient provided informed consent. Ethical approval for this study was waived of as it is not considered a human medical research.

\section{Consent for Publication}

Written informed consent was obtained from the patient for publication of this case report and any accompanying images.

\section{Acknowledgments}

We would like to thank Editage for English language editing.

\section{Author Contributions}

All authors made a significant contribution to the work reported, whether that is in the conception, study design, execution, acquisition of data, analysis and interpretation, or in all these areas; took part in drafting, revising or critically reviewing the article; gave final approval of the version to be published; agreed on the journal to which the article has been submitted; and agree to be accountable for all aspects of the work.

\section{Funding}

There is no funding to report.

\section{Disclosure}

The authors declare no conflicts of interest.

\section{References}

1. Kuet ML, Kasbekar AV, Masterson L, Jani P. Management of tumors arising from the parapharyngeal space: a systematic review of 1293 cases reported over 25 years. Laryngoscope. 2015;125(6):1372-1381. doi:10.1002/lary.25077

2. López F, Suárez C, Vander Poorten V, et al. Contemporary management of primary parapharyngeal space tumors. Head Neck. 2019;41(2):522-535. doi:10.1002/hed.25439

3. Tsunoda A, Kishimoto S, Tou M, et al. Endoscopy-aided combined intraoral and cervical approach for a huge parapharyngeal benign tumor. Ear Nose Throat J. 2021;100(10_suppl):1041S-1044S. doi:10.1177/0145561320935834

4. Vinayagam S, Dhanger S, Tilak P, Gnanasekar R. C-MAC ${ }^{\circledR}$ video laryngoscope with D-BLADETM and Frova introducer for awake intubation in a patient with parapharyngeal mass. Saudi J Anaesth. 2016;10(4):471-473. doi:10.4103/1658-354X.179118

5. Apfelbaum JL, Hagberg CA, Caplan RA, et al.; American Society of Anesthesiologists Task Force on Management of the Difficult Airway. Practice Guidelines for Management of the Difficult Airway: an Updated Report by the American Society of Anesthesiologists Task Force on Management of the Difficult Airway. Anesthesiology. 2013;118(2):251-270. doi:10.1097/ALN.0b013e31827773b2

6. Japanese Society of Anesthesiologists. JSA airway management guideline 2014: to improve the safety of induction of anesthesia. $J$ Anesth. 2014;28 (4):482-493. doi:10.1007/s00540-014-1844-4

7. Wong DT, Mehta A, Tam AD, Yau B, Wong J. A survey of Canadian anesthesiologists' preferences in difficult intubation and "cannot intubate, cannot ventilate" situations. Can J Anaesth. 2014;61(8):717-726. doi:10.1007/s12630-014-0183-0

8. Ji SM. Difficult airway management in a patient with a parapharyngeal tumor. J Dent Anesthesiol Pain Med. 2015;15:153-156. doi:10.17245/ jdapm.2015.15.3.153

International Medical Case Reports Journal

Dovepress

\section{Publish your work in this journal}

The International Medical Case Reports Journal is an international, peer-reviewed open-access journal publishing original case reports from all medical specialties. Previously unpublished medical posters are also accepted relating to any area of clinical or preclinical science. Submissions should not normally exceed 2,000 words or 4 published pages including figures, diagrams and references. The manuscript management system is completely online and includes a very quick and fair peer-review system, which is all easy to use. Visit http://www.dovepress.com/testimonials. php to read real quotes from published authors.

Submit your manuscript here: https://www.dovepress.com/international-medical-case-reports-journal-journal 